\title{
Comparison between Depression levels of Adolescent Boys and their Selected Family Background Variables
}

\author{
Parvati Shinde ${ }^{1}$ and Ramana Desetty ${ }^{2}$ \\ 1 Postgraduate, Dept. of Human Development \& Family Studies, College of Home \\ Science, Marathwada Agril. University, Parbhani-431402 (Maharastra), India \\ 2 Associate Professor, Dept. of Human Development \& Family Studies, College of \\ Home Science, Marathwada Agril. University, Parbhani-431402 (Maharastra), India
}

\begin{abstract}
Two hundred adolescent boys in the age group of 16-18 yrs, studying in std. X, XI, XII were chosen at random from purposely selected seven schools and colleges Parbhani town, Maharashtra State. Their depression levels were assessed by administering depression scale of Karim and Tiwari and their background information related to the study was collected through personal interview. Out of the 200 adolescent boys, 100 of them hailed from low SES and the remaining to middle SES group. The results indicates that majority (83\%) of the selected adolescent boys were assessed to have low level depression followed by moderate (8\%) and high(8\%) level of depression irrespective of the socioeconomic status of the family. The background variables like family size, family type, socio-economic status, relationship with parents and siblings were found to have significant influence on the depression levels of adolescent boys.
\end{abstract}

Keywords: Adolescent Boys, Depression levels

\section{Introduction}

As every individual is a part of family from birth to throughout in life, as it plays an important role in personality development of adolescents but at the same time the family also the influencing factor for adolescents' depression. Lewinjohn et al. (1998) and Sheeber et al. (1998) stated that depression in adolescence is often associated with the absence of supportive and positive interactions with parents and is characterized by elevated levels of conflictual, critical and angry interactions. Depression arises from poor family relations that could include decreased family support and perceived rejection by parents (Lasko et al., 1996). Parental behaviour has significant impact on personality development of children in growing stages because the children spend much more time at home with their parents. So parental strict behaviour leads poor mental health in children.

Having emotionally stable parents is a boon for children because parental emotional condition influences their children's emotional health. Hammen and Brennan, ( 2001 ) studied the relation between depressed adolescents and depressed mothers and found that the depressed children of depressed mothers had more negative interpersonal relationships as compared with depressed children of non-depressed mothers. Because of negative interpersonal relations between parents and their kids, children can develop a negative view of their family. Further, Chen et al. (1995) reported that the parents of depressed children are less warm and caring and more hostile than parents of nondepressed children. In light of above it was felt necessary to take up the study on Comparison Between Depression levels of Adolescent Boys and their Family Background Variables.

\section{Methodology}

Two hundred adolescent boys in the age range of 16-18 yrs, studying in std. X, XI, XII were chosen at random from purposely selected seven schools and colleges of Parbhani town, Parbhani District of Maharashtra state. The adolescent students' depression was assessed by administering Depression Scale of Karim and Tiwari and their background information was elicited through the personal interview. Out of 200, adolescent boys 100 of them belonged to low SES and the remaining to middle SES group. The information collected from the selected adolescent boys through personal interviews and by administering the depression scale was pooled, tabulated, analyzed statically and discussed below. 


\section{Results and Discussion}

Table 1 indicates that, irrespective of the SES of family, majority (83\%) of the selected adolescent boys were assessed to have low level depression followed by moderate (8\%) and high(8\%) level of depression . Significantly a higher percentage of low SES group respondents were found to be the victims of depression at high level as compared to their counterparts from middle SES group. This clearly shows that the low SES group parents failed to fulfill the needs of their growing sons. These findings are in line with the findings quoted in the research study of Ritsher et al. (2008) which is a signal to parents to fulfill the psychological needs of their growing sons and to maintain warm relations.

Table 1 Depression levels of adolescent boys and its relation with SES groups

\begin{tabular}{|l|c|c|c|c|}
\hline \multirow{2}{*}{$\begin{array}{c}\text { Assessed levels } \\
\text { of depression }\end{array}$} & $\begin{array}{c}\text { Total adolescent boys } \\
(\mathbf{2 0 0})\end{array}$ & $\begin{array}{c}\text { Low SES (100) } \\
\text { (a) }\end{array}$ & $\begin{array}{c}\text { Middle SES } \\
(\mathbf{1 0 0}) \\
(\mathbf{b})\end{array}$ & a Vs b \\
\hline Low & $83.00(166)$ & $45.18(75)$ & $54.81(91)$ & $0.55^{\mathrm{NS}}$ \\
\hline Moderate & $8.50(17)$ & $64.70(11)$ & $35.29(6)$ & $1.81^{\mathrm{NS}}$ \\
\hline High & $8.50(17)$ & $82.35(14)$ & $17.64(3)$ & $6.30^{* *}$ \\
\hline
\end{tabular}

Figures in parenthesis indicate numbers of the adolescent boys

**- P > 0.01 level NS - Non significant

From table 2, it is clearly noted that, out of all the low SES group adolescent boys, who were assessed to have high level of depression, majority (57\%) of them belonged to nuclear families followed by joint families (28\%) and extended families (14\%). Similar trend of results were noted with regard to the victims of depression at low level $(46,37$ and $16 \%)$ and partially similar trend of results were noted about the victims of depression at moderate level $(45 \%, 18 \%, 36 \%)$. On the other hand, in among the middle SES group adolescent boys having high and low level depression, majority of them hailed from nuclear families (66\%-56\%) and fifty percent adolescent boys had moderate level of depression were found to be in joint families. The reasons for this might be due to parental ignorance about the consequences of depression on their growing children. Therefore, it is a signal for parents of nuclear families to observe their sons closely for knowing the signs of depression and taking preventive measures from experts to overcome such problem. These findings are in agreement with the findings reported by Sethi et al. (1967) and Sethi and Sharma (1980) with regarding to adolescents having high level of depression belonged to nuclear families. Statistical analysis indicates that family type was found to have influence on low level of depression of adolescent boys.

Table 3 illustrates the comparison between depression levels of adolescent boys and their family size. In low SES group, significantly a higher percentage of adolescent boys hailed from medium size families were found to be in low level depression as compared to their counterparts belonged to small and large size families. Similar trend of results were noted even in case of the selected respondents of middle SES group. This clearly shows that there is communication gap between male adolescents and their parents who belonged to medium size families and also parents unable to fulfill the basic needs of their growing sons might be due to more number of members in the family i.e 5-8. This result is in accordance with the result mentioned in the research study carried out by Khan et al. (2008). However, significant difference was not noted between depression levels of the selected adolescent boys the size of their families.

Table 4 depicts Comparison between depression levels of adolescent boys and their perception about relationships with parents. It is obvious to note that sixty six and forty two percent middle and low SES groups adolescent boys were rated to have high level depression had perceived their relationship with parents was at frictional level as compared to their counterparts having neutral relationships (33-50\%) and warm relationships (7\%). Among moderate level of depressed category adolescent boys thirty three percent of the middle SES group and 45 percent of the low SES group adolescent boys stated to have frictional relations with their parents followed by neutral relations (16-36\%) and warm relationship (18\% and 50\%). On the other hand the results are vice versa with regard to mild level depressed adolescents of both the SES groups' i.e. warm relations (81-85\%) between adolescent boys and parents SES groups. 
Over all it can be concluded that due to generation gap and communication gap between parents and children, due to lack of parental knowledge and understanding about the basic needs of growing children etc. might be the contributing factors for adolescent boys having conflicts with their parents which all ultimately led them to fall prey to various levels of depression. But at the same time having understanding parents and having warm relationship with parents which might be the strong support for them to have good mental health. Significant difference was noted between adolescent boys' low and high depression levels and their perception on relationships with parents. The results are in line with the findings stated by Thallia et al. (2004) with regard to frictional relations leveled high depression.

Comparison between depression levels of adolescent boys and their perception on relationships with siblings is given in table 5. It is clear from results that among low SES group, 42, 54 and 6 percent adolescent boys having high, moderate and low levels of depression were found to have always frictional relationship followed by neutral relationship (28, 36 and $17 \%)$ and warm relationship $(28,9$ and $76 \%$ ) with their siblings. On the other hand, in middle SES group 33, 83 and 1 percent of them were assessed to have high, moderate and low levels of depression perceived their relation with siblings was frictional followed by neutral $(33,16$ and $23 \%$ ) and warm relations (33\%high, $78 \%$-low) with their siblings. Communication gap, parental favoritism etc. might be contributing factors for creating conflicts among siblings which all might have elevated the depression level in them. On the other hand good communication, understand, cooperative behavior among siblings might be responsible for them to have low depression. Few significant differences were found in both the SES group adolescent boys irrespective of their relation with siblings and their depression levels. However there is no significant difference between low and medium SES groups adolescent boys irrespective of their relation with siblings and their depression levels.

\section{References}

[1]. Chen, X., Rubin, K. H., \& Li, B. (1995). Depressed moods in Chinese children: Relations with school performance and family environment. Journal of Consulting and Clinical Psychology, 63, 938-947.

[2]. Khan, S., Ahamad, S. and Arshad, N. (2006). Birth order, family size and its association with conversation disorder. Pak J. Med. Sci., 22 (1): $38-42$.

[3]. Lasko, D.S., Field, T.M., Gonzalez, K.D., Harding, J., Yando, R. and Bendell, D. (1996).Adolescent depressed mood parental unhappiness. J. Adolescence, 31(121): 49-47.

[4]. Lewinsohn, P., Rohde and Seeley (1998). Cited in Adolescent depression, family psychopathology and parent/child relations: a case control study by Seguin, M., Manion, J., Clutier, P., Mcevey, L. and Cappelli, M. (2003). J. Child Adolescence Pscyhatric Rev., 12(1):29 .

[5]. Ritsher, J. (2001). Inter-generational longitudinal study of social class and depression: a test of social causation and social selection models. The British J. Psychiatry, 178:84-90.

[6]. Sethi, B.B. and Sharma, M. (1980). Depressive disorder and family constellation. Indian J. Psychiatry, 22(1):69-73.

[7]. Sethi, B.B., Gupta, S.C. and Kumar, R. (1967). 300 urban families. A psychiatric study. Indian J. of Psychiatry, 9(4):280-302.

[8]. Sheeber, L., Hops H., Alpert, A., Davis, B.Z. and Annadrews, J. (1998). Family support and conflict prospective relation to adolescent depression, website: http://www.springerlind.comm/content/m8 .

[9]. Thallia, E., Holan, L., Robert, P., Pak, S., Abram, S., Richard, W. and Shaun, P. (2004). Parental familial vulnerability, family environment and their interactions. As predictor of depressive symptoms in adolescents. Journal of the American Academy of Child and Adolescent psychiatry, 43(3):298-306.

Table 2 Comparison between depression levels of adolescent boys and their family type

\begin{tabular}{|c|c|c|c|c|c|c|c|c|}
\hline \multirow{3}{*}{$\begin{array}{l}\text { Depression } \\
\text { levels of } \\
\text { adolescent } \\
\text { boys }\end{array}$} & \multicolumn{8}{|c|}{ SES and family types of the adolescent boys } \\
\hline & \multicolumn{4}{|c|}{ Low SES (100) } & \multicolumn{4}{|c|}{ Middle SES (100) } \\
\hline & $\mathbf{n}$ & $\begin{array}{l}\text { Nuclear } \\
\text { (a) }\end{array}$ & $\begin{array}{c}\text { Joint } \\
\text { (b) }\end{array}$ & $\begin{array}{l}\text { Extended } \\
\text { (c) }\end{array}$ & $\mathbf{n}$ & $\begin{array}{l}\text { Nuclear } \\
\text { (d) }\end{array}$ & $\begin{array}{c}\text { Joint } \\
\text { (e) }\end{array}$ & $\begin{array}{l}\text { Extended } \\
\text { (f) }\end{array}$ \\
\hline Low & 75 & $46.66(35)$ & $37.33(28)$ & $16.00(12)$ & 91 & $56.52(52)$ & $31.86(29)$ & $10.98(10)$ \\
\hline Moderate & 11 & $45.45(5)$ & $18.18(2)$ & $36.36(4)$ & 6 & $33.33(2)$ & $50.00(3)$ & $16.66(1)$ \\
\hline High & 14 & $57.14(8)$ & $28.57(4)$ & $14.28(2)$ & 3 & $66.66(2)$ & $33.33(1)$ & - \\
\hline
\end{tabular}

z values

\begin{tabular}{|c|c|c|c|c|c|c|c|c|c|}
\hline $\begin{array}{c}\text { Depression } \\
\text { levels }\end{array}$ & a Vs b & b Vsc & c Vs a & d Vse & e Vs f & f Vs d & a Vsd & b Vse & c Vsf \\
\hline Low & $0.12^{\mathrm{NS}}$ & $3.00 * *$ & $4.28 * *$ & $3.57 * *$ & $3.57 * *$ & $7.66 * *$ & $2.25^{*}$ & $0.86^{\mathrm{NS}}$ & $1.20^{\mathrm{NS}}$ \\
\hline Moderate & $-\ldots$ & ב.... & -..- & $\ldots$ & -ב.-- & -..- & -.- & -..-- & ב..- \\
\hline High & -..- & ב-... & - & $\ldots$ & ב-ב & -ב- & $\ldots$ & -...- & ב-.. \\
\hline
\end{tabular}

Figures in parenthesis indicate numbers of the adolescent boys

*- $\mathrm{P}>0.05$ level **- $\mathrm{P}>0.01$ level NS - Non significant 
Table 3 Comparison between depression levels of adolescent boys and their family size

\begin{tabular}{|c|c|c|c|c|c|c|c|c|}
\hline \multirow{3}{*}{$\begin{array}{l}\text { Depression levels } \\
\text { of adolescent } \\
\text { boys }\end{array}$} & \multicolumn{8}{|c|}{ SES and family size of the adolescent boys } \\
\hline & \multirow[t]{2}{*}{ n } & \multicolumn{3}{|c|}{ Low SES (100) } & \multirow[t]{2}{*}{$\mathbf{n}$} & \multicolumn{3}{|c|}{ Middle SES (100) } \\
\hline & & $\begin{array}{l}\text { Small } \\
\text { (a) }\end{array}$ & $\begin{array}{l}\text { Medium } \\
\text { (b) }\end{array}$ & $\begin{array}{l}\text { Large } \\
\text { (c) }\end{array}$ & & $\begin{array}{l}\text { Small } \\
\text { (d) }\end{array}$ & $\begin{array}{l}\text { Medium } \\
\text { (e) }\end{array}$ & $\begin{array}{l}\text { Large } \\
\text { (f) }\end{array}$ \\
\hline Low & 75 & $20.00(15)$ & $74.66(56)$ & $5.33(4)$ & 91 & $32.96(30)$ & $63.73(58)$ & $3.29(3)$ \\
\hline Moderate & 11 & $54.54(6)$ & $45.45(5)$ & -- & 6 & -- & $83.33(5)$ & $16.66(1)$ \\
\hline High & 14 & $21.42(3)$ & $71.42(10)$ & $7.14(1)$ & 3 & -- & $66.66(2)$ & $33.33(1)$ \\
\hline
\end{tabular}

zValues

\begin{tabular}{|c|c|c|c|c|c|c|c|c|c|}
\hline Depression levels & a Vs b & bVsc & $\mathrm{cVsa}$ & dVse & eVsf & $d V_{s} f$ & a Vsd & bVse & $\mathrm{cVs}$ \\
\hline Low & $7.71 * *$ & $13.80^{* *}$ & $3.00 * *$ & $4.42^{* * *}$ & $12.00 * *$ & $5.80 * *$ & $1.71^{\mathrm{NS}}$ & $1.57^{\mathrm{NS}}$ & $0.66^{\mathrm{N}}$ \\
\hline Moderate & -- & -- & - & $\ldots$ & $\ldots$ & $\ldots$ & $\ldots$ & $\ldots$ & $\ldots$ \\
\hline High & -- & $\ldots$ & - & -- & $\ldots$ & $\ldots$ & -- & -- & -- \\
\hline
\end{tabular}

Figures in parenthesis indicate numbers of the adolescent boys

**. $\mathrm{P}>0.01$ level NS - Non significant

Table 4 Comparison between depression levels of the adolescent boys and about their perception on relationships with parents

\begin{tabular}{|l|c|c|c|c|c|c|c|c|}
\hline \multirow{2}{*}{$\begin{array}{l}\text { Depression levels of } \\
\text { adolescent boys }\end{array}$} & \multicolumn{9}{|c|}{ Low SES (100) } \\
\cline { 2 - 9 } & $\mathbf{n}$ & $\begin{array}{c}\text { Warm } \\
\text { (a) }\end{array}$ & $\begin{array}{c}\text { Neutral } \\
\text { (b) }\end{array}$ & $\begin{array}{c}\text { Frictional } \\
\text { (c) }\end{array}$ & $\mathbf{n}$ & $\begin{array}{c}\text { Warm } \\
\text { (d) }\end{array}$ & $\begin{array}{c}\text { Neutral } \\
(\mathrm{e})\end{array}$ & $\begin{array}{c}\text { Frictional } \\
\text { (f) }\end{array}$ \\
\hline Low & 75 & $81.23(61)$ & $18.66(14)$ & -- & 91 & $85.71(78)$ & $13.18(12)$ & -- \\
\hline Moderate & 11 & $18.18(2)$ & $36.36(4)$ & $45.45(5)$ & 6 & $50.00(3)$ & $16.66(1)$ & $33.33(2)$ \\
\hline High & 14 & $7.14(1)$ & $50.00(7)$ & $42.85(6)$ & 3 & --- & $33.33(1)$ & $66.66(2)$ \\
\hline
\end{tabular}

$\mathbf{z}$ values

\begin{tabular}{|c|c|c|c|c|c|c|c|c|c|}
\hline $\begin{array}{c}\text { Depression } \\
\text { levels }\end{array}$ & a Vsb & bVsc & cVsa & dVse & $\mathrm{eVsf}$ & f Vsd & aVsd & bVse & $\mathrm{cVsf}$ \\
\hline Low & $10.5^{* *}$ &.- & $\ldots$ & $14.4^{* *}$ & $\ldots$ & --- & $0.666^{\mathrm{NS}}$ & $0.83 \mathrm{NS}$ & $\ldots$ \\
\hline Moderate & $1.00^{\mathrm{NS}}$ & $0.45^{\mathrm{NS}}$ & $1.50^{\mathrm{NS}}$ & $1.36^{\mathrm{NS}}$ & 0.70 & $0.68 \mathrm{NS}$ & $1.39 \mathrm{NS}$ & $1.00^{\mathrm{NS}}$ & $0.50^{\mathrm{NS}}$ \\
\hline High & $2.86 * *$ & $0.44^{\mathrm{NS}}$ & $2.50^{*}$ &.- & $0.86 \mathrm{Ns}$ & $\ldots$ & $\ldots$ & $0.56^{\mathrm{NS}}$ & $0.80^{\mathrm{NS}}$ \\
\hline
\end{tabular}

Figures in parenthesis indicate numbers of the adolescent boys

$*$ - $P>0.05$ level **. $P>0.01$ level NS - Non significant

Table 5 Comparison between depression levels of the adolescent boys and their perception on relationships with siblings

$\mathbf{z}$ values

\begin{tabular}{|l|c|c|c|c|c|c|c|c|c|}
\hline $\begin{array}{c}\text { Depression } \\
\text { levels }\end{array}$ & a Vs b & b Vs c & c Vs a & d Vs e & e Vs f & f Vs d & a Vs d & b Vs e & c Vs f \\
\hline Low & $9.83^{* *}$ & $2.20^{*}$ & $14.00^{* *}$ & $9.67^{* *}$ & $4.75^{* *}$ & $19.25^{* *}$ & $0.33^{\mathrm{NS}}$ & $0.50^{\mathrm{NS}}$ & $1.67^{\mathrm{NS}}$ \\
\hline Moderate & $1.86^{\mathrm{NS}}$ & $0.90^{\mathrm{NS}}$ & $2.64^{* *}$ & --- & $3.19^{* *}$ & --- & --- & $0.95^{\mathrm{NS}}$ & $1.38^{\mathrm{NS}}$ \\
\hline High & --- & $0.82^{\mathrm{NS}}$ & $0.82^{\mathrm{NS}}$ & --- & --- & --- & $0.17^{\mathrm{NS}}$ & $0.17^{\mathrm{NS}}$ & $3.00^{* *}$ \\
\hline
\end{tabular}

Figures in parenthesis indicate numbers of the adolescent boys

$*_{-} \mathrm{P}>0.05$ level $*_{*} *_{-} \mathrm{P}>0$

.01 level NS - Non signifa 